\title{
OPTIMIZATION OF SPEED CHANGES AND ITS EFFECTS ON RUNNING TIME AND CAPACITY
}

\author{
WIEBKE LENZE \& NILS NIEßEN \\ Institute of Transport Science, RWTH Aachen University, Germany
}

\begin{abstract}
In modern train control systems such as ETCS Level 2, cab signalling replaces the usual stationary trackside signalling. The display of permissible speeds on the cab itself allows a relocation of the speed change from the signal to the actual point of danger - in this paper the start of a switch. Additionally, it is possible to display the speed as an exact value instead of an indicator rounded down to the nearest ten. The investigation of several switches shows that optimized speed changes can significantly reduce the running time. In a result, minimum headway times are decreased and hence the capacity is increased. Requiring less running time for a section makes it possible to carry out more train movements with the same operating quality or to improve the operating quality for an unchanged number of trains.
\end{abstract}

Keywords: ETCS, signalling, speed changes, switch, travel time, capacity.

\section{INTRODUCTION}

Europe is facing an increasing demand for transportation. In order to meet this demand, the rail network needs to provide more capacity. Due to limited possibilities of infrastructure expansions, it is necessary to optimize the use of the existing infrastructure.

The European Commission promoted the European Train Control System (ETCS) for use throughout Europe in order to support interoperable cross-border traffic. ETCS is an automatic train protection system based on cab signalling. For ETCS Level 2 the track to train data transmission is continuous. All signal aspects are displayed in the cab and train movements are monitored continually. Therefore, trackside signalling may be dispensed [1].

Speed changes can be optimized when using ETCS Level 2. The cab signalling allows for a signalling of speed reductions at the actual point of danger instead of the signal. Most speed reductions are necessary when driving on the diverging track of a switch. Reducing the speed at the start of the switch instead of a few hundred metres before at the signal location, allows the train to drive this distance at the higher speed.

In addition to the relocation of speed changes, cab signalling makes it possible to signal the speed as an exact value. In this way, the permissible speed for driving on the diverging track of a switch may be increased. The German railway network includes more than 65,000 switches, which represent a considerable potential for optimized speed changes [2].

The outline of this paper is as follows: First, an overview of methods to determine the capacity of railway lines is given. Then it is described how speed changes are commonly indicated. Based on this knowledge two options to optimize speed changes are presented and investigated on a sample line. After analysing the effects on travel time and capacity, the paper concludes with a summary.

\section{METHOD}

This section gives an overview of the current state of scientific progress and common methods to calculate the capacity, which have been used in the exemplary in Chapter 5. 


\subsection{Infrastructure occupancy}

The usage of the infrastructure can be described based on calculated running and blocking times. The operational occupancy of a section takes longer than the purely physical occupancy. Before the train enters a section, it is already blocked for the route setup time $t_{\text {setup }}$, the signal watching time $t_{\text {sight }}$ and the approach time $t_{\text {approach }}$. After the actual running time $t_{\text {running }}$, the clearing time $t_{\text {clearing }}$ and the release time $t_{\text {release }}$ are taken into account before the section can be released for the next train movement. The sum of these time elements, which are shown in Fig. 1, is referred to as blocking time [3].

The graphic sequence of a train's blocking times of track sections forms a blocking time stairway. With blocking time stairways, the temporal distance in which two trains can follow in the densest possible train sequence free of obstruction can be determined for each overtaking section. This duration is called minimum headway time and is measured from the beginning of the blocking time of the preceding train until the beginning of the blocking time of the subsequent train. The overtaking section with the largest minimum headway time is decisive for the entire track. Minimum headway times are input variables for an analytical determination of the line capacity [4].

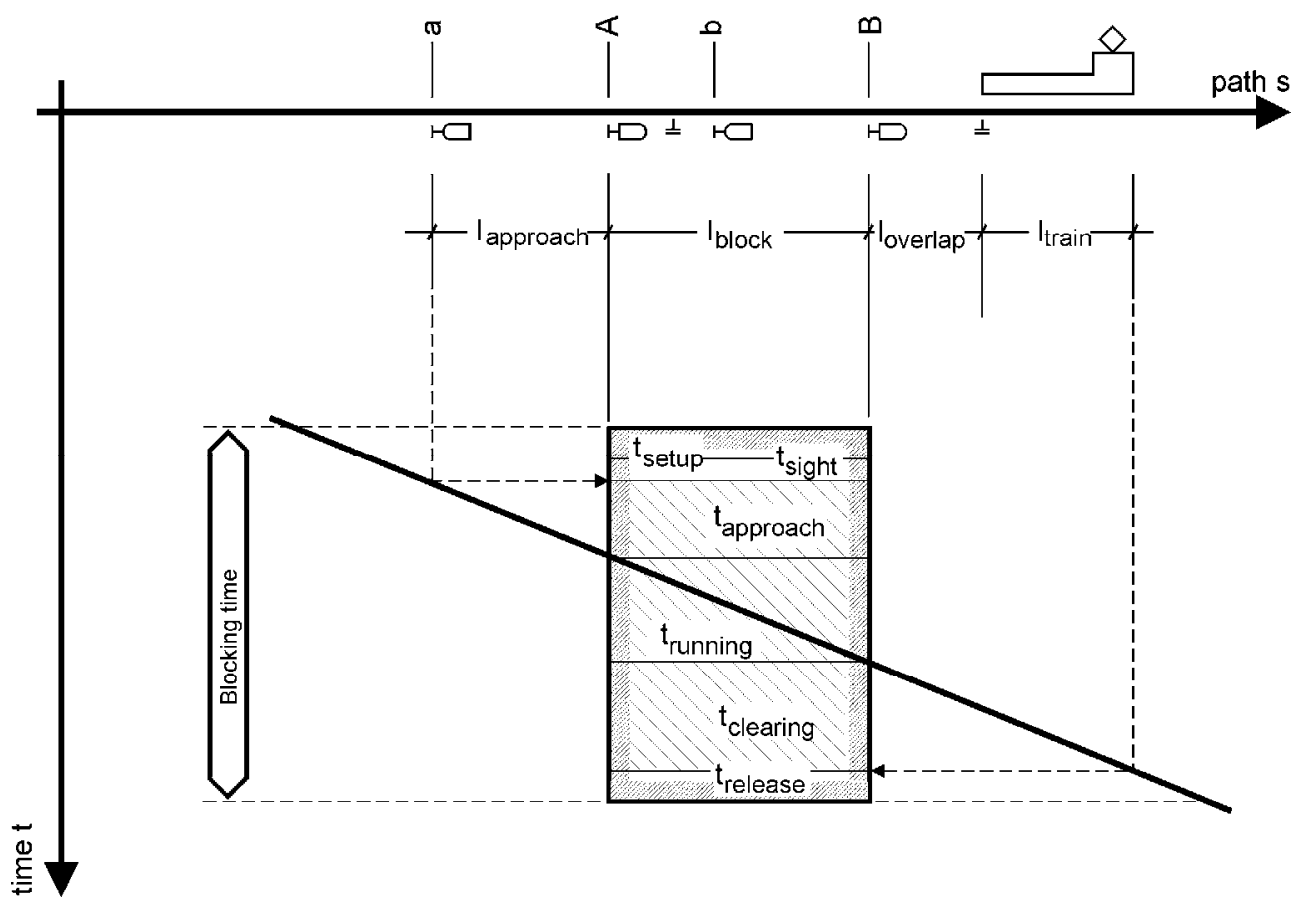

Figure 1: Blocking time elements. 


\subsection{Capacity of railway lines}

Capacity describes the number of train movements that can be carried out on a railway line within a certain period, in accordance with a defined quality level.

According to UIC leaflet 406 [5], the performance of a line is determined by using blocking times to identify the concatenated occupancy rate. For this purpose, blocking times are compressed without considering buffer times (see Fig. 2). The concatenated occupancy rate then results from the ratio of the occupancy time to the investigation period. The occupancy time can also be used to determine the optimum number of trains (optimal capacity) for an occupancy rate of $60 \%$ (for mixed-traffic lines) as suggested in the leaflet.

Another method for determining capacity parameters is the timetable-independent analytical method of queuing theory. The STRELE-formula allows to estimate knock-on delays during operation depending on the initial delays at the start of the route. The calculated values can be contrasted with permissible waiting times in order to determine the capacity for an economically optimal operating quality. This method is mainly used in Germany [6].

\section{CURRENT SPEED CHANGES}

In the railway system, permissible line speeds are documented in a timetable and must be observed by the train driver. At the entrance to railway stations, different pre-set routes can be used to reach station tracks, often at different speeds. This is where a signalling or indication of the permissible speed takes place. Historically, signals display the permissible speed as indicators rounded down to the nearest ten. Rounding the speed reduces the number of potential displayed indicators and simplifies the visual reception by the train driver. Speed indicators at signals display a number whose ten times value in $\mathrm{km} / \mathrm{h}$ has to be observed as the speed from the signal and must not be exceeded [7]. This means that the permissible speed might be up to $9 \mathrm{~km} / \mathrm{h}$ below the theoretically permissible speed. Other signals authorize the driver to pass at a certain speed indicated by a set of lights. Since it is only possible
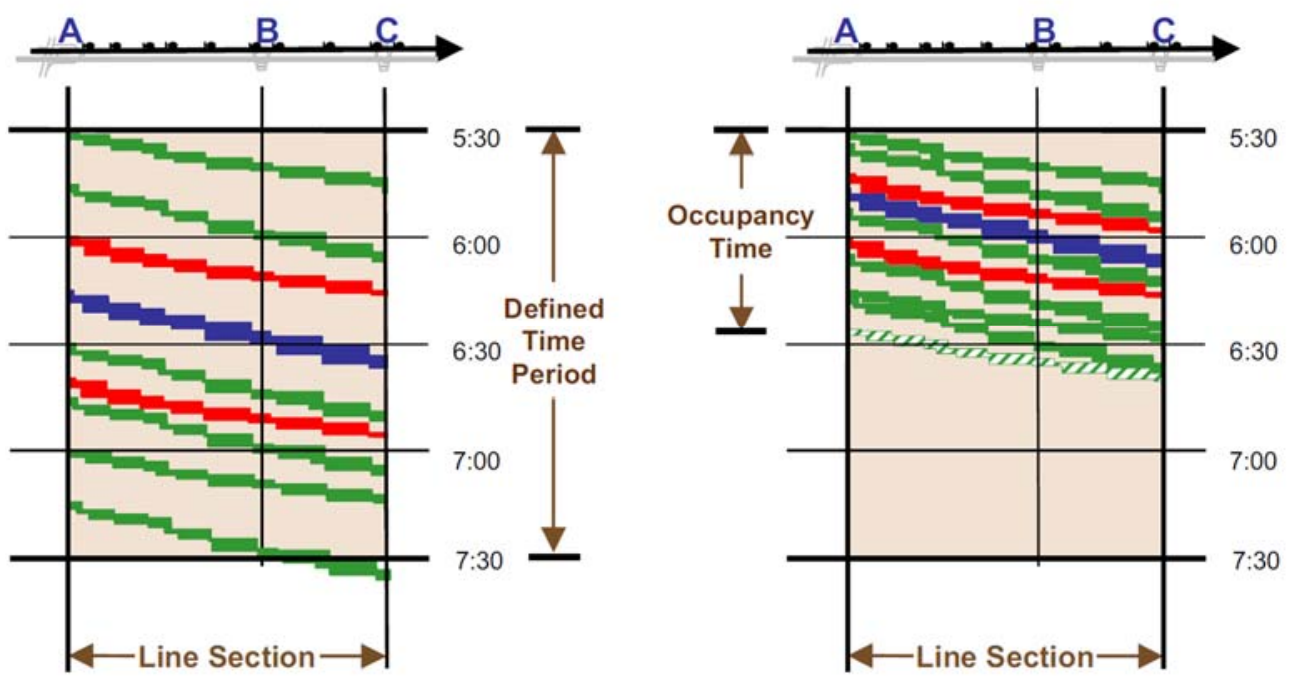

Figure 2: Compression in accordance with UIC Code 406 [5]. 
to indicate a limited number of different speeds, this kind of signalling holds the same limitations as signals with numbers as speed indicators.

In most cases, speed reductions occur when driving on the diverging track of switches. The permissible rounded down speeds $v_{1}$ for the diverging track of basic types of switches as indicated in the German directive Ril 800 of DB Netz AG [8] are shown in Table 1 for common switch radii. The following chapter explains how the exact speed $v_{2}$ is calculated.

\section{OPTIMIZING SPEED CHANGES}

In modern train control systems such as ETCS Level 2, cab signalling can replace the usual stationary trackside signalling. Cab signalling allows the exact display of the speed instead of indicating the rounded down to ten value. In addition, the display of the permissible speed on cabs allows the transfer of speed changes from the signal to the actual point of danger the switch start.

In Fig. 3, both the relocation of the speed change and the speed reduction to the exact permissible speed are illustrated. In this example, the line speed is $230 \mathrm{~km} / \mathrm{h}$. A speed reduction is necessary to enter the station track on the diverging track of a switch with a radius $r_{0}$ of $500 \mathrm{~m}$. The black line indicates the speed reduction to $60 \mathrm{~km} / \mathrm{h}$ at the signal. The optimized speed change is represented by the green line. Instead of a reduction to $60 \mathrm{~km} / \mathrm{h}$ the speed only has to be reduced to $67 \mathrm{~km} / \mathrm{h}$. Furthermore, the speed reduction is relocated from the signal to the start of the turnout. These two possibilities to optimize speed changes are described in the following.

Table 1: Permissible speed for basic types of switches.

\begin{tabular}{|l|l|l|l|}
\hline Radius $r_{0}[\mathrm{~m}]$ & $\begin{array}{l}\text { Rounded down } \\
\text { speed } v_{1}[\mathrm{~km} / \mathrm{h}]\end{array}$ & $\begin{array}{l}\text { Exact speed } \\
v_{2}[\mathrm{~km} / \mathrm{h}]\end{array}$ & $\begin{array}{l}\text { Speed difference } \\
\Delta v[\mathrm{~km} / \mathrm{h}]\end{array}$ \\
\hline 190 & 40 & 41 & 1 \\
\hline 300 & 50 & 52 & 2 \\
\hline 500 & 60 & 67 & 7 \\
\hline 760 & 80 & 83 & 3 \\
\hline 1200 & 100 & 103 & 3 \\
\hline 2500 & 130 & 138 & 8 \\
\hline
\end{tabular}

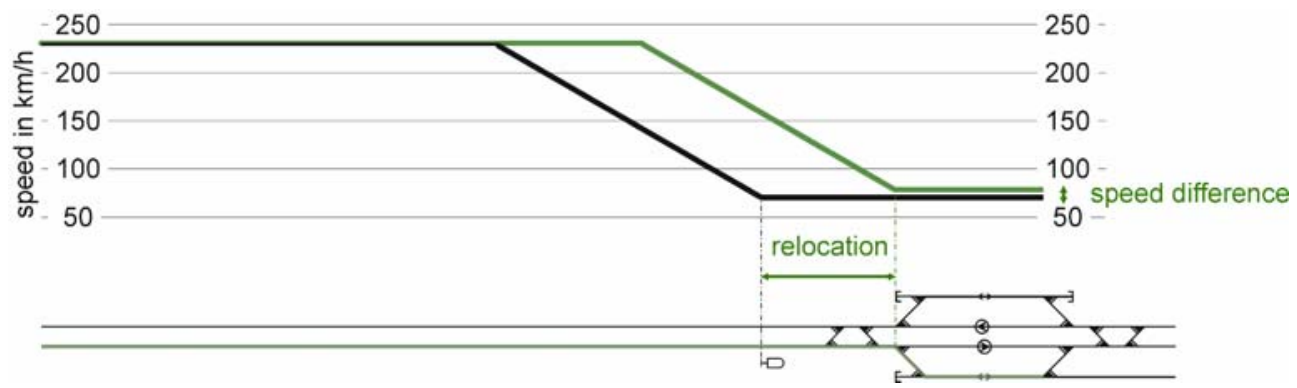

Figure 3: Example of an optimized speed change. 


\subsection{Exact permissible speeds}

Technically, the permissible speed on the diverging track is higher than the rounded down value $v_{1}$. In order to determine the maximum permissible speed of a switch on the diverging track both the proof of superelevation and the proof of jerk must be observed.

The permissible speed per $v$ as defined for the proof of superelevation can be calculated according to the following formula [8]:

$$
\operatorname{per} v \leq \sqrt{\frac{r_{Z}}{11,8} \cdot\left(\operatorname{per} u_{f}+u\right)}
$$

where

per $v$ : permissible speed in $\mathrm{km} / \mathrm{h}$

$r_{Z}: \quad$ diverging track radius in $\mathrm{m}$

per $u_{f}$ : cant deficiency in $\mathrm{mm}$

$u: \quad$ cant in $\mathrm{mm}$

$r_{W}=r_{0} r_{W} r_{0}$

The proof of jerk limits the amount of lateral acceleration during a change of curvature. Fig. 4 shows the maximum permissible speed depending on the reference radius $r_{W}$ for the fulfilment of the proof of jerk. The reference radius equals the radius of the basic type of the switch for standard and curved switches.

$$
r_{W}=r_{0}
$$

where

$r_{W}: \quad$ reference radius

$r_{0}: \quad$ radius of the basic type of the switch

Technically permissible speeds $v_{2}$ in accordance with the proof of superelevation and proof of jerk were calculated for standard switches without cant and contrasted with the rounded values $v_{1}$ in Table 1 . The speed difference $\Delta v$ is greatest at switches with a radius of the basic type $r_{0}$ of $500 \mathrm{~m}$ and $2,500 \mathrm{~m}$.

The technically permissible speed for switches with a radius of the basic type of $r_{0}=500 \mathrm{~m}$ is $67 \mathrm{~km} / \mathrm{h}$ thus $7 \mathrm{~km} / \mathrm{h}$ higher than the currently used permissible speed of $60 \mathrm{~km} / \mathrm{h}$. The time difference increases linearly with the distance. Driving $1,000 \mathrm{~m}$ at a speed of $67 \mathrm{~km} / \mathrm{h}$ instead of $60 \mathrm{~km} / \mathrm{h}$ saves around $6 \mathrm{~s}$ whereas the time difference increases to nearly $13 \mathrm{~s}$ for a distance of $2,000 \mathrm{~m}$.

\subsection{Relocating speed reductions}

Changing the location of a speed reduction from the signal to the actual point of danger - the start of a switch - allows the train to continue driving at a higher speed up to the switch. The time saved depends on the relocation as well as the line speed and speed reduction.

Fig. 5 shows the running time over distance for a line speed of $230 \mathrm{~km} / \mathrm{h}$ and for the permissible speeds $v_{2}$ of basic types of switches. When driving at a speed of $230 \mathrm{~km} / \mathrm{h}$ it takes around $16 \mathrm{~s}$ to travel a distance of $1,000 \mathrm{~m}$. With a speed of $67 \mathrm{~km} / \mathrm{h}$, it takes around $54 \mathrm{~s}$ to travel the same distance. Consequently, $38 \mathrm{~s}$ are saved when the speed reduction from $230 \mathrm{~km} / \mathrm{h}$ to $67 \mathrm{~km} / \mathrm{h}$ is relocated by $1000 \mathrm{~m}$. It is most effective to relocate speed changes at lines with high permitted speeds when the distance between signal and switch is large. 


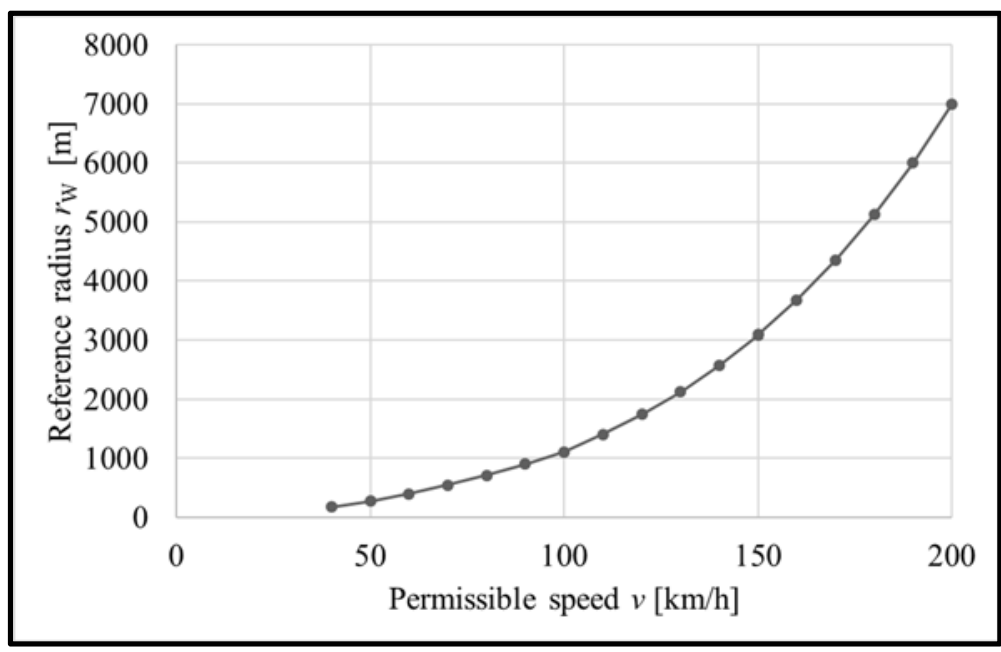

Figure 4: Permissible speed $v$ in relation to the reference radius $r_{\mathrm{W}}$.

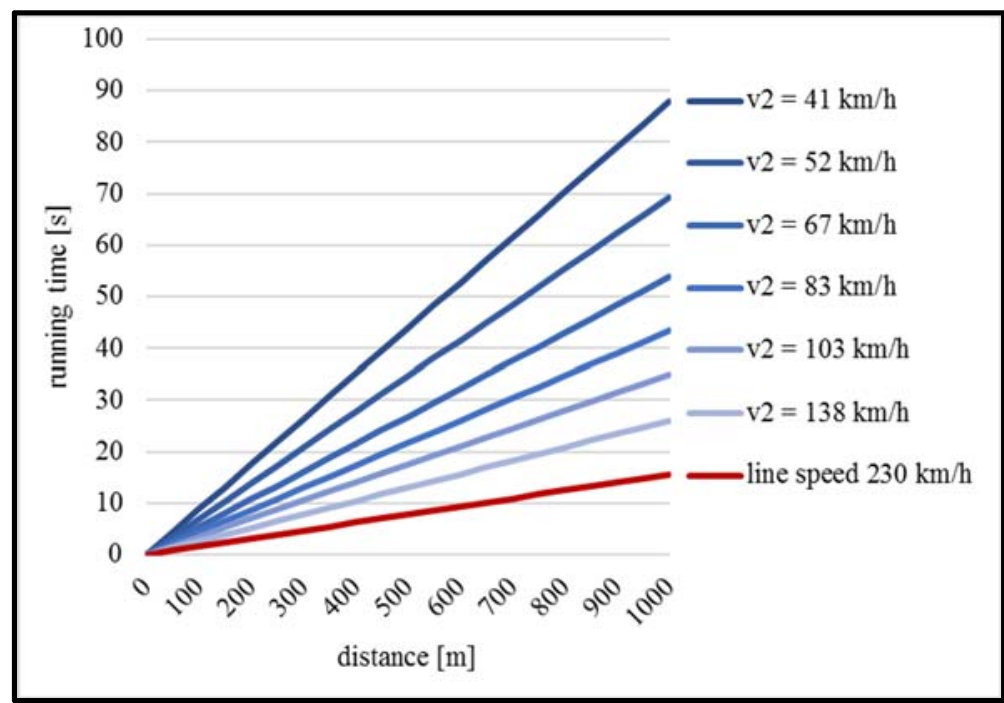

Figure 5: Running time for different speeds.

\section{EXAMPLE}

In this chapter, a sample line is used to investigate the impact of modified speed changes on running time and capacity.

\subsection{Input}

Running time and capacity can be determined with the help of the software LUKS $^{\circledR}$. LUKS $^{\circledR}$ is a software for the analysis of railway junctions and lines. It was developed in cooperation with the former engineering company Schultze Wakob and Partners (now Schultze + Gast 
Ingenieure) and the Institute of Transport Science at RWTH Aachen University. In 2008, VIA Consulting \& Development GmbH took over the support and maintenance of the software [9].

A $50 \mathrm{~km}$ generic sample line was created to determine the impact on running time and capacity. Between the two stations A-City and B-City lie evenly distributed three passing stations $\mathrm{P} 1-\mathrm{P} 3$. All overtaking tracks are accessible via switches with a diverging track radius of $500 \mathrm{~m}$ and have a sufficient operational length. The microscopic track diagram is depicted in Fig. 6.

Five different trains per hour run on the line with a maximum permissible line speed of $230 \mathrm{~km} / \mathrm{h}$ (see Table 2). In A-City and B-City all trains stop at least $2 \mathrm{~min}$. The passenger trains have additional stops at the passing stations: The regional trains RE stop at the passing station P2 and the RB stop at all station P1 - P3. The long-distance trains (ICE) overtake the regional trains $\mathrm{RB}$ during the stop at passing station $\mathrm{P} 2$.

This operating programme was investigated using different scenarios. In the initial scenario 1 , (entry) signals display speed reductions. This corresponds to the standard procedure for intermittent train control (ITC). Due to the diverging track radii of $500 \mathrm{~m}$, using overtaking tracks is allowed at a speed $v_{1}$ of $60 \mathrm{~km} / \mathrm{h}$ according to Table 1.

Scenario 2 is based on cab signalling which is possible using a train control system such as ETCS Level 2. The permissible speed $v_{1}$ of $60 \mathrm{~km} / \mathrm{h}$ is indicated at the start of the switch instead of the signal. Additionally, to the different location of a speed reduction, in scenario 3 the indicated speed at the switch is changed to the technically permissible speed $v_{2}$ of 67 $\mathrm{km} / \mathrm{h}$.

The sample line was investigated in all three scenarios varying the distance between signals and switches. This distance takes values of $250 \mathrm{~m}, 500 \mathrm{~m}$ and 1,000 m. With these three

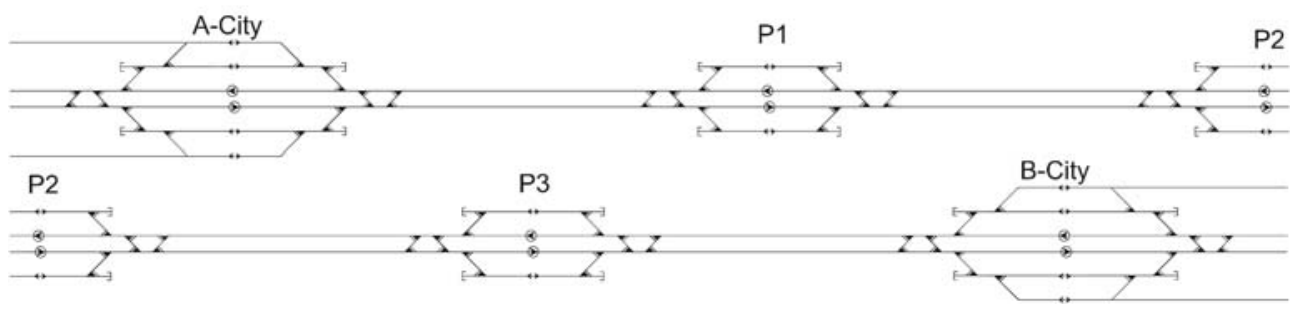

Figure 6: Track diagram.

Table 2: Operating programme.

\begin{tabular}{|l|l|l|l|l|l|l|}
\hline Train & Maximum speed & \multicolumn{5}{|c|}{ Dwell time [min] } \\
\cline { 3 - 7 } & of the train $[\mathrm{km} / \mathrm{h}]$ & A-City & P1 & P2 & P3 & B-City \\
\hline ICE & 250 & 2 & & & & 2 \\
\hline IC & 200 & 2 & & & & 2 \\
\hline RE & 160 & 2 & & 2 & & 2 \\
\hline RB & 140 & 2 & 2 & 5 & 2 & 2 \\
\hline FT & 140 & 5 & & & & 5 \\
\hline
\end{tabular}


scenarios in three different variations of the infrastructure, it is possible to investigate the impact of both possible optimizations for speed changes: Increasing the permissible speed to the technically exact value and relocating the speed change from the signal to the actual point of danger depending on the distance between them.

\subsection{Impact on running time}

The running time was calculated for all three scenarios. In order not to obtain restrictions on running time determination by train control systems, it was stated that the exit signal is already set when entering a station.

Table 3 depicts the running times of all trains between A-City and B-City. It shows that optimized speed changes can reduce the running time by up to $3.5 \mathrm{~min}$. For the $\mathrm{RB}$, running time profits are greatest, as this train stops at every passing station. Each drive into an overtaking track leads over switches with a reduced permissible speed of 60 or $67 \mathrm{~km} / \mathrm{h}$. The ICE however never uses an overtaking track and therefore never has to reduce its speed.

The distance between signal and switch only affects the running time in scenario 1 , in which signals indicate the permitted speed. In the scenarios 2 and 3 the reduced speed is indicated at the switch. Therefore, the distance between signal and switch cannot affect the running time.

The running time profit, on the one hand, can be used to realize shorter travel times. On the other hand, the original travel times can be maintained, so that the time difference is used as travel times reserves to increase the operating quality.

Table 3: Running times of all trains.

\begin{tabular}{|l|l|l|l|l|}
\hline Relocation & Train & Scenario 1 & Scenario 2 & Scenario 3 \\
\hline \multirow{5}{*}{$250 \mathrm{~m}$} & ICE & $00: 21: 37$ & $00: 21: 37$ & $00: 21: 37$ \\
\cline { 2 - 5 } & IC & $00: 24: 57$ & $00: 24: 49$ & $00: 24: 21$ \\
\cline { 2 - 5 } & RE & $00: 31: 45$ & $00: 31: 34$ & $00: 30: 56$ \\
\cline { 2 - 5 } & RB & $00: 44: 13$ & $00: 43: 58$ & $00: 42: 57$ \\
\cline { 2 - 5 } & FT & $00: 37: 25$ & $00: 37: 22$ & $00: 37: 13$ \\
\hline \multirow{5}{*}{$500 \mathrm{~m}$} & ICE & $00: 21: 37$ & $00: 21: 37$ & $00: 21: 37$ \\
\cline { 2 - 5 } & IC & $00: 25: 18$ & $00: 24: 49$ & $00: 24: 21$ \\
\cline { 2 - 5 } & RE & $00: 32: 15$ & $00: 31: 34$ & $00: 30: 56$ \\
\cline { 2 - 5 } & RB & $00: 44: 59$ & $00: 43: 58$ & $00: 42: 57$ \\
\cline { 2 - 5 } & FT & $00: 37: 34$ & $00: 37: 22$ & $00: 37: 13$ \\
\hline \multirow{5}{*}{$1,000 \mathrm{~m}$} & ICE & $00: 21: 37$ & $00: 21: 37$ & $00: 21: 37$ \\
\cline { 2 - 5 } & IC & $00: 25: 59$ & $00: 24: 49$ & $00: 24: 21$ \\
\cline { 2 - 5 } & RE & $00: 33: 10$ & $00: 31: 34$ & $00: 30: 56$ \\
\cline { 2 - 5 } & RB & $00: 46: 23$ & $00: 43: 58$ & $00: 42: 57$ \\
\cline { 2 - 5 } & FT & $00: 37: 51$ & $00: 37: 22$ & $00: 37: 13$ \\
\hline
\end{tabular}


Table 4: Capacity according to UIC Code 406 and its changes compared to scenario 1.

\begin{tabular}{|l|l|l|l|l|l|}
\hline Relocation & Scenario 1 & Scenario 2 & $\begin{array}{l}\text { Difference to } \\
\text { Scenario 1 }\end{array}$ & & $\begin{array}{l}\text { Sifference to } \\
\text { Scenario 1 }\end{array}$ \\
\hline $250 \mathrm{~m}$ & 159 & 163 & $+3 \%$ & 166 & $+4 \%$ \\
\hline $500 \mathrm{~m}$ & 169 & 180 & $+7 \%$ & 185 & $+9 \%$ \\
\hline $1000 \mathrm{~m}$ & 159 & 179 & $+13 \%$ & 184 & $+16 \%$ \\
\hline
\end{tabular}

\subsection{Impact on capacity}

The optimal capacity was determined for a 24-hour investigation period using the two methods described in chapter 2. In order to exclude the influence of train control systems, ETCS Level 2 was assumed for all calculations.

Table 4 presents the capacity calculated as defined in UIC Code 406 . The results show that optimized speed changes increase the capacity significantly. Both the relocation of the speed reduction (scenario 2) and the additional speed change from 60 to $67 \mathrm{~km} / \mathrm{h}$ (scenario 3) have a positive impact on the capacity. These two scenarios were compared to scenario 1. Most notably for larger distances between signal and switch, the impact of the relocation predominates. When applying the STRELE-formula to calculate the capacity the results are very similar.

Scenario 3 combines both options to modify speed changes and therefore provides the optimal capacity. Compared to scenario 1 the capacity increases by up to $16 \%$. That means it allows the traffic of 25 additional trains per day.

\section{SUMMARY}

The increasing demand for transportation on rail networks requires an optimal use of the existing infrastructure. Modifying speed changes poses an opportunity to improve the performance of a rail network without expanding it.

The cab signalling which is used for ETCS Level 2 can indicate the exact permitted speed instead of a value rounded down to the nearest ten. Therefore, it is possible for the train to drive at a higher speed. Another aspect when optimizing speed changes is allowing the train not to reduce the speed until it has reached the actual point of danger. Especially when the distance between signal and switch is large, this has a significant effect.

Optimized speed changes with enhanced signalling systems result in the train to drive at higher speed for a longer time. This has positive impact not only on the running time but also on the capacity. Thus, a higher demand for transportation can be satisfied at unchanged operating quality or the operating quality can be improved for an unchanged traffic.

\section{REFERENCES}

[1] ETCS, Union Internationale Des Chemins De Fer. https://uic.org/etcs. Accessed on: 6 Apr. 2018.

[2] Deutsche Bahn, A.G., Infrastrukturzustands- und -entwicklungsbericht, 2016.

[3] Pachl, J., Timetable design principles. Railway Timetabling \& Operations, eds I.A. Hansen \& J. Pachl, Eurailpress: Hamburg, pp. 13-46, 2014.

[4] Nießen, N., Queueing. Railway Timetabling \& Operations, eds I.A. Hansen \& J. Pachl, Eurailpress: Hamburg, pp. 117-131, 2014.

[5] UIC Code 406: Capacity, 2nd ed., Jun. 2013. 
[6] DB Netz AG: Richtlinie 405 - Fahrwegkapazität, Berlin, 2009.

[7] DB Netz AG: Richtlinie 301 - Signalbuch, Frankfurt am Main, 2015.

[8] DB Netz AG: Richtlinie 800 - Netzinfrastruktur Technik entwerfen, Frankfurt am Main, 2015.

[9] Janecek, D. \& Weymann, F., LUKS - Analysis of lines and junctions. Proceedings of the 12th World Conference on Transport Research (WCTR), Lisbon, 2010. 